\title{
Modelo conceitual para a compreensão da ansiedade na performance musical ${ }^{*}$ A conceptual framework for understanding musical performance anxiety
}

\author{
Ioulia Papageorgi** \\ University of Nicosia, Cyprus \\ papageorgi.@unic.ac.cy \\ Susan Hallam ${ }^{* * *}$ \\ UCL Institute of Education, University College London, London, UK \\ s.hallam@ucl.ac.uk \\ Graham Welch ${ }^{* * * *}$ \\ UCL Institute of Education, University College London, London, UK \\ graham.welch@ucl.ac.uk \\ Tradução: \\ Fernanda T. Zanon***** \\ Universidade Federal de Minas Gerais (UFMG), Brasil \\ fecazanon@gmail.com
}

\begin{abstract}
* Tradução do texto original intitulado "A conceptual framework for understanding musical performance anxiety", publicado no periódico Research Studies in Music Education, v. 28, n. 1, p. 83-107, 2007. Aparece aqui sob a permissão da primeira autora loulia Papageorgi.
\end{abstract}

** Dra. loulia Papageorgi é professora associada do Departamento de Ciências Sociais da Universidade de Nicósia e diretora do Instituto de Ensino e Aprendizagem da Universidade de Nicósia (UNTLI). Ocupou os cargos de professora e coordenadora de pesquisas no Instituto de Educação da UCL, Universidade de Londres (2006-2011), e de professora associada na Open University (Reino Unido) (2009-2011).

*** Susan Hallam é professora emérita de Educação e Psicologia da Música no Instituto de Educação da UCL, University College London. Desenvolveu sua carreira como musicista profissional e educadora musical antes de se tornar acadêmica em 1991. Sua pesquisa se concentrou em questões relacionadas à aprendizagem e aos benefícios da música.

**** Graham Welch é presidente fundador de Educação Musical do Instituto de Educação da UCL, University College London, desde 2001. É presidente anterior da Sociedade Internacional de Educação Musical (ISME) (2008-2014) e é presidente eleito da Sociedade de Educação, Música e Psicologia (SEMPRE). Suas publicações abrangem o desenvolvimento musical e a educação musical, a formação de professores, a psicologia da música, o canto e a ciência da voz e a música na educação especial.

***** Fernanda Zanon é mestre em Música pela Universidade de Aveiro (Portugal) e doutoranda pela Universidade Federal de Minas Gerais (UFMG), sob orientação da Dra. Patrícia Furst Santiago. É bacharel em Piano e licenciada em Música pela Universidade Federal de Minas Gerais (UFMG). 
Podemos observar um aumento significativo em pesquisas na área da ansiedade na performance musical. Um problema tão comum e que afeta tantos músicos precisa ser debatido visando a melhoria da saúde dessa população. A tradução do texto de Papageorgi, Hallam e Welch (2007) para o português do Brasil contribui para a difusão, compreensão profunda e esclarecimentos sólidos sobre esta temática. Ao refletirmos sobre a ansiedade na performance musical e pensarmos em caminhos para lidar com ela tanto em nossas práticas em sala de aula como em nossas práticas performativas, pretendemos contribuir substancialmente para as áreas da educação musical, performance, ensino e aprendizagem do instrumento, bem como nos transformarmos enquanto músicos.

\section{Resumo}

A maior parte das pesquisas realizadas sobre Ansiedade na Performance Musical (APM) tem considerado sua relação com as características internas do intérprete musical, a condição de preparação para a performance e fatores relativos ao ambiente no momento da execução. Os métodos para o seu alívio geralmente têm natureza clínica. Poucas pesquisas situam-se ao redor de um modelo conceitual explícito e abrangente. Este artigo propõe um quadro teórico que retrata a ansiedade no contexto da performance musical como um processo que tem uma dimensão clara de tempo (pré-, durante e pós-performance). O modelo ilustra os prováveis processos que ocorrem a partir do momento em que um artista concorda em participar de uma performance específica e explica como eles podem dar origem tanto a formas mal adaptativas quanto adaptativas da ansiedade na performance. Os efeitos potenciais a longo prazo sobre o artista também são discutidos. Uma descrição detalhada do modelo e as teorias por trás do seu desenvolvimento são seguidas por uma consideração das implicações do modelo e da sua potencial utilidade para pesquisa e educação.

Palavras-chave: Ansiedade na performance musical. Saúde do músico. Performance musical. Educação musical.*

\section{Abstract}

Most research on musical performance anxiety has considered this in relation to the internal characteristics of the performer, the extent of their preparedness for the performance, and factors in the immediate performing environment. The approach to its alleviation has generally been clinical in nature. Little research has been situated within an explicit overarching conceptual framework. This article proposes a theoretical framework that portrays anxiety within a musical performance context as a process that has an explicit time dimension (pre-, during- and post-performance). The model illustrates the likely processes that occur once a performer agrees to participate in a particular performance and explains how these might give rise to either maladaptive or adaptive forms of performance anxiety. The potential longer-term effects on the performer are also discussed. A detailed description of the model and the theories behind its development is followed by a consideration of model's implications and potential usefulness for both research and education.

Keywords: Music Performance Anxiety; Musicians' Health; Music Performance; Music Education*

* No artigo original, as palavras-chave não foram destacadas. 


\section{Introdução}

Pesquisas sobre ansiedade na performance musical cresceram em número nas duas últimas décadas. Muitas clínicas, revistas e conferências se empenharam em estudar os aspectos psicológicos e médicos da performance musical (VALENTINE, 2002, p. 168). Parece haver dois motivos fundamentais para isso. $O$ primeiro diz respeito a uma elevada incidência de ansiedade mal adaptativa na pré-performance de músicos, e o segundo relaciona-se com o fato de serem reconhecidos os efeitos debilitantes que a ansiedade pode causar tanto na performance quanto no bem-estar do performer ${ }^{1}$ (STEPTOE, 2001). As pesquisas mais recentes têm como foco principal o diagnóstico, a avaliação e o tratamento da ansiedade mal adaptativa na performance, isto é, lidar com a ansiedade debilitante que tem um impacto negativo na qualidade do tocar. Os resultados das pesquisas facilitaram o desenvolvimento em contextos clínicos de uma série de estratégias de enfrentamento, como terapia cognitivo-comportamental, meditação, hipnoterapia, biofeedback, diálogo interno positivo e Técnica Alexander (para revisões de técnicas que foram propostas para aliviar a ansiedade na performance musical, veja GABRIELSSON, 1999; HALLAM, 2003; KENNY, 2005; SALMON; MEYER, 1998; WILLIAMON, 2004; WILSON, 2002).

Contudo, houve uma tendência de as descobertas no campo não se situarem dentro de um modelo unificado e coerente sobre o qual estudos posteriores pudessem se embasar. Consequentemente, poderia ser útil se houvesse uma teoria que incorporasse a fenomenologia, correlatos e consequências da ansiedade, enquanto também destacasse a complexa interdependência de causa e efeito nas relações entre ansiedade na performance musical e outras variáveis relacionadas. Tal perspectiva teórica pode permitir uma maior compreensão do processo envolvido na APM e, ao mesmo tempo, oferecer um guia para educadores, músicos e pesquisadores para encontrarem formas adequadas de lidar com problemas de má adaptação. Paralelamente, a construção desse quadro conceitual pode facilitar e promover o conhecimento no campo da APM e potencialmente fornecer informações valiosas aos processos realizados em uma perspectiva individual do performer. Ter o indivíduo como foco é importante, já que nem todos são igualmente afetados ou respondem da mesma forma aos contextos que podem originar a ansiedade. Este artigo visa a oferecer um modelo conceitual através da literatura relacionada à temática. Fatores que contribuem são classificados em três categorias: (i) fatores que influenciam a predisposição do performer em vivenciar a ansiedade na performance; (ii) fatores que influenciam sua autoeficácia; e (iii) fatores relacionados com o ambiente da performance. Os potenciais efeitos da ansiedade na qualidade da performance são descritos, e teorias são apresentadas sobre a relação entre a excitação fisiológica e a eficiência da performance. 


\section{Fatores que contribuem para o aumento da ansiedade na performance}

\section{(i) Fatores que influenciam a predisposição do performer em vivenciar a ansiedade na performance}

O grau de predisposição para vivenciar a ansiedade tem um papel importante na performance, pois pode influenciar as percepções do performer em relação à situação e aos seus procedimentos de preparação. A predisposição e o grau de sensibilidade à ansiedade são características atribuídas ao artista, nas quais podem ser incluídas características intrínsecas, extrínsecas e cognitivas. Características intrínsecas do performer incluem gênero, idade, personalidade, ansiedade-traço, ${ }^{2}$ sensibilidade à avaliação de outras pessoas, crenças de autoeficácia ${ }^{3}$ e seus autoconceitos. ${ }^{4}$ Outras características individuais extrínsecas e/ou de situações específicas podem incluir o nível ou extensão da experiência de desempenho individual e a qualidade de experiências semelhantes anteriores. As características cognitivas do artista também podem influenciar a sua vulnerabilidade à ansiedade na performance, incluindo a inteligência, o estilo cognitivo, as habilidades metacognitivas, ${ }^{5}$ o estilo de atribuição, ${ }^{6}$ as crenças sobre a aprendizagem e a capacidade, e suas expectativas sobre os resultados. ${ }^{7}$ Cada um desses recursos é descrito brevemente abaixo.

\section{Gênero}

O gênero do performer tem sido relacionado à predisposição à ansiedade. Mulheres são consideradas mais propensas a um alto grau de ansiedade na performance (ABEL; LARKIN, 1990, ABRAMS; MANSTEAD, 1981) e a conceberem a presença do

2 Ansiedade-traço pode ser definida como uma predisposição geral a ser ansioso; já a ansiedade-estado varia de acordo com os tipos de situação em que o indivíduo se encontra (SINICO, Andre; WINTER, Leonardo L. Ansiedade na performance musical: causas, sintomas e estratégias de estudantes de flauta. Opus, Porto Alegre, v. 19, n. 1, p. 239-264, jun. 2013.

3 A autoeficácia tem sido descrita como a crença na própria capacidade de planejar e executar as ações necessárias para lidar com situações futuras (BANDURA, 1977 apud OREJUDO, Santos et al. The relation of music performance anxiety (MPA) to optimism, self-efficacy, and sensitivity to reward and punishment: Testing Barlow's theory of personal vulnerability on a sample of Spanish music students. Psychology of Music 2017, v. 45, n. 4, p. 570-583, 2017).

40 autoconceito pode ser definido de forma simples, como a percepção que o indivíduo tem de si próprio e o conceito que, devido a isso, forma de si (SERRA, A. O auto-conceito. Análise Psicológica, v. 2, n. 6, p. 101, 1988).

5 A metacognição se refere ao conhecimento do aprendiz sobre a própria aprendizagem (isto é, pensar sobre o pensamento). Isso é fundamental para a prática. As habilidades metacognitivas estão relacionadas com o planejamento, o monitoramento e a avaliação da aprendizagem, incluindo o conhecimento de pontos fortes e fracos, estratégias disponíveis (orientadas para tarefas e orientadas para as pessoas) e conhecimento de domínio para avaliar a natureza da tarefa e avaliar o progresso em direção ao objetivo (BARRY, N. H.; HALLAM, S. Practice. In: PARNCUTT, R.; McPHERSON, G. The Science and Psychology of Music Performance. Creative Strategies for Teaching and Learning. New York: Oxford University Press, 2002. p. 151-165. DOI: 10.1093/acprof:oso/9780195138108.003.0010

6 Crenças sobre as causas do sucesso e do fracasso podem influenciar uma variedade de comportamentos futuros de realização, expectativas, autopercepções e outras respostas emocionais. Em pesquisas sobre estilo de atribuição, os teóricos exploram o impacto dessas crenças nas expectativas de sucesso futuro e nas percepções individuais de suas próprias habilidades e da dificuldade das várias tarefas. Cf. O’NEILL, S.A.; McPHERSON, G.E. Motivation. In: PARNCUTT, R.; McPHERSON, G. E. (Eds.). The Science \& Psychology of Music Performance. New York: Oxford University Press, 2002. p. 36.

$7 \quad 0$ outro construto central na teoria da autoeficácia é a expectativa de resultados. Expectativa sobre o resultado é definida como a estimativa de uma pessoa de que determinado comportamento levará a certos resultados. De acordo com a teoria de autoeficácia, as expectativas de resultados são claramente diferenciadas da autoeficácia, porque a autoeficácia é a capacidade percebida de fazer um comportamento, enquanto as expectativas de resultado são julgamentos sobre a probabilidade de resultados que fluem do comportamento (BANDURA, A. Social Learning Theory. Englewood Cliffs, NJ: Prentice Hall, 1977). 
público como mais ameaçadora (LEBLANC et al., 1997). Estudos recentes relativos a crianças e adolescentes músicos reforçam as descobertas de que, em comparação aos homens, as mulheres são consideradas mais ansiosas e suscetíveis a sentirem ansiedade mal adaptativa na performance (KENNY; OSBORNE, 2006; RAE; McCAMBRIDGE, 2004; RYAN, 2004; PAPAGEORGI, 2007).

\section{Idade}

Pesquisas têm demonstrado que a idade também contribui para tornar o indivíduo mais propenso à ansiedade. Ao longo do tempo, as pessoas não permanecem igualmente vulneráveis a ela, e a adolescência parece ser um período particularmente problemático (HALLAM, 1998; LEBLANC, 1994; PAPAGEORGI, 2007). Para alguns artistas profissionais, a ansiedade continua sendo um desafio ao longo da vida adulta (FISHBEIN et al., 1988; SCHULZ, 1981; STEPTOE, 2001).

\section{Diferenças individuais e fatores da personalidade}

Kemp argumenta que nosso temperamento musical ${ }^{8}$ é dominado por uma interdependência entre diferentes fatores, como a introversão, a independência, a sensibilidade e a ansiedade (KEMP, 1996). A introversão tem sido considerada um atributo útil nas performances, já que se acredita que ela aumente "uma habilidade de aprofundar-se numa mentalidade interna de cores e imaginação, ao mesmo tempo propiciando uma determinação necessária para a aquisição de habilidade técnica (KEMP, 1981, p. 12). Porém, a introversão também pode ser um grande indutor para a ansiedade, considerando que os introvertidos parecem ter menos controle sobre o estresse (KEMP, 1996). Isto sugere que não podem lidar de maneira tão efetiva com níveis altos de excitação. Os traços de introversão da personalidade e de neuroticismo, características encontradas em padrões de personalidades de músicos, correlatam com a ansiedade na performance (KEMP, 1981, 1996). O traço de introversão da personalidade parece estar ligado ao aumento dos níveis de ansiedade. Há a necessidade de interação, de tocar como uma atividade social na presença de outras pessoas, e isso contrasta com a frequente solidão e a rotina prática do performer.

A baixa autoestima tem sido considerada uma das origens da ansiedade na performance. Apesar de poder ser iniciada em função de uma performance ruim, ela também pode estar enraizada em sentimentos profundos de desvalorização pessoal (REUBART, 1985). Em certos casos, "um incidente menos importante pode dar origem a uma ansiedade excessiva a cada vez que a ameaça da performance deve ser enfrentada" (REUBART, 1985, p. 34).

Padrões excessivamente altos e perfeccionismo também estão associados à debilidade na performance (MOR et al., 1995). O perfeccionismo, a predisposição irreal a expectativas muito altas em si próprio e/ou nos outros e o excesso de preocupação em relação a pequenos erros podem aumentar a predisposição à ansiedade na performance (WILSON; ROLAND, 2002).

\footnotetext{
8 Temperamento musical pode ser definido como características pessoais que fazem parte da personalidade e do temperamento do músico (introversão, independência, sensibilidade, ansiedade e questões de gênero, por exemplo) e que influenciam nas diferentes formas de musicalidade (como tocar, cantar e reger orquestrais). O livro The Musical Temperament, de Anthony Kemp, esclarece as maneiras pelas quais habilidades específicas impactam o desenvolvimento da personalidade ou predispõem a pessoa a diferentes instrumentos e estilos de performance.
} 
Ansiedade-traço

Muitos autores (KEMP, 1996; REUBART, 1985; WILSON, 2002) têm sustentado a ideia de que há uma relação importante entre o "traço" de ansiedade em um indivíduo - o quão propenso à ansiedade é o indivíduo - e a "ansiedade-estado" evidenciada - o nível de ansiedade em uma situação específica. De acordo com Wilson (2002), algumas pessoas são mais sensíveis que outras em relação à avaliação negativa e ao medo de falhar. Tais pessoas encaram as situações avaliativas, a exemplo de recitais e exames, como mais ameaçadoras e desafiadoras. Uma série de estudos mostra uma correlação positiva entre ansiedade-traço e ansiedade na performance musical (COX; KENARDY, 1993; HAMANN, 1982).

\section{Autoconceito negativo}

Acredita-se que o autoconceito seja visto como uma visão multifacetada de si mesmo, que é formada através de experiências diretas e avaliações feitas por pessoas influenciadoras (BANDURA, 1997). Em relação à música, um autoconceito positivo tem sido relacionado à competência percebida em habilidades performativas (DEWS; WILLIAMS, 1989; PRUETT, 1991; TOBACYK; DOWNS, 1986). A aquisição de um autoconceito positivo na música pode ser importante para manter a confiança e a autoestima altas, características que constituem uma defesa contra a experiência da ansiedade mal adaptativa na performance musical (PAPAGEORGI, 2007).

Baixa autoeficácia

A autoeficácia é definida como "[...]a crença na capacidade individual para organizar e executar as ações requeridas para a realização das tarefas a serem cumpridas" (BANDURA, 1997, p.3). A autoeficácia e a ansiedade estão relacionadas, uma vez que a confiança na capacidade em desempenhar uma determinada tarefa interage com uma ansiedade subjetiva, autonômica e comportamental do indivíduo (BANDURA, 1977). A diminuição da confiança na habilidade de tocar tem sido discutida como a causa de pensamentos de autossabotagem, angústia, diminuição do controle emocional e aumento da excitação (BANDURA, 1982). Isso está de acordo com a visão de que autoeficácia e expectativas por resultados são conceitualizadas como precursores significantes de ansiedade e ansiedade de teste (SCHWARZER; JERUSALEM, 1992). No contexto da performance musical, julgamentos de autoeficácia podem variar de acordo com a dificuldade da peça a ser tocada, autocompetência musical percebida em relação à performance daquela peça e às circunstâncias ambientais (avaliação, concerto, recital, performance pública informal). Autoeficácia em música envolve crenças não só sobre tocar um instrumento ou peça musical de forma bem-sucedida, mas também em tocar uma seção particularmente difícil com êxito. Estudos sobre autoeficácia em música sugerem que alta autoeficácia gera um impacto positivo na realização de exames de nível, em geral (McCORMICK; McPHERSON, 2003; McPHERSON; McCORMICK, 1999, 2006).

Sensibilidade à avaliação de terceiros

As exigências e as altas expectativas dos professores e da família também são motivos que podem resultar em sentimentos de inadequação e nervosismo (GABRIELSSON, 1999).

9 O nervosismo pode ser caracterizado como uma sensação que desaparece após o momento de tensão, sendo muito comum e presente em uma situação de performance pública. 
Além do medo de ser avaliado negativamente, a esperança e as expectativas não correspondidas podem desencadear nervosismo. As preocupações a respeito das reações de outras pessoas à performance estão certamente correlacionadas à ansiedade (LEHRER et al., 1990).

\section{Teoria entitária sobre a habilidade}

Dweck (2000) tem afirmado que a autoestima é mais vulnerável quando as pessoas possuem uma teoria entitária ao invés de uma teoria incrementalista de suas habilidades (i.e., quando as pessoas veem suas habilidades como rígidas, ao invés de maleáveis). Sugere-se que tais indivíduos são propensos a serem mais impotentes, considerando que acreditam que as circunstâncias estão além de seus controles, sendo assim, desistem mais facilmente ou tentam menos arduamente. Os teoristas entitários tendem a desenvolver objetivos baseados em tocar melhor que os outros e em evitar o fracasso (DWECK, 2000). Para as pessoas que seguem a teoria entitária, a possibilidade da falha ameaça a autoestima, já que isto indiciaria que falta nessa pessoa uma habilidade em questão, ou mesmo que ela jamais virá a tê-la. Em contrapartida, para as pessoas que seguem a teoria incremental, o fracasso não é tão devastador, pois essas pessoas tendem a acreditar que, apesar de não possuírem a habilidade em questão naquele momento, essa deficiência pode ser resolvida através do aumento dos seus esforços (HONG et al., 1999). O'Neill (2002) sugere que, no que concerne a habilidades para a performance musical, um indivíduo pode tanto endossar a teoria entitária, acreditando que as pessoas são dotadas de um certo "talento musical", como a teoria incremental, que diz que qualquer pessoa pode desenvolver suas habilidades através do esforço e da prática.

\section{Expectativas sobre resultados negativos}

As expectativas sobre resultados no contexto das performances musicais podem influenciar a vulnerabilidade de uma pessoa à sensação de ansiedade. Os modelos de expectativa (MAGNUSSON; STATTIN, 1981; PEKRUN, 1985) afirmam que as cognições (pensamentos) que provocam a ansiedade são influenciadas pelas características do ambiente externo aos testes (tais como dificuldades das tarefas, tempo, adequação à preparação) e pelas características individuais de quem está vivendo a situação (em termos de suas expectativas sobre o sucesso e o fracasso, a percepção da probabilidade do fracasso, nível de aspiração e a percepção da importância da tarefa). Tem-se discutido que o nível de ansiedade depende da quantidade de ameaça percebida resultante de um evento (negativo), da avaliação subjetiva da probabilidade do evento e pela habilidade individual percebida para a prevenção do evento (PEKRUN, 1985.).

\section{Atribuição de valor às realizações}

Weiner (1985) sugere que diferentes formas de atribuição de valor às realizações (i.e., explicações causais de sucessos e fracassos pessoais) estão relacionadas a diferentes efeitos: afetivos, cognitivos e motivacionais. Uma atribuição causal do indivíduo sobre realizações e fracassos pode afetar seus comportamentos e motivação subsequentes, suas expectativas sobre futuras realizações e sua persistência em relação a tarefas similares. Quando eventos positivos são vistos como resultado de causas internas, estáveis e/ 
ou controláveis (Ex.: habilidade) e eventos negativos são explicados em relação a termos externos, instáveis e causas que não podem ser controladas (Ex.: circunstâncias de sorte ou azar), o indivíduo se sente mais otimista em relação a um futuro sucesso em tarefas similares. Por outro lado, quando eventos negativos são explicados em termos internos, estáveis e controláveis (como a habilidade), e eventos positivos em termos de causas externas, instáveis e não controláveis (como sorte e tarefas fáceis), os indivíduos se sentem pessimistas em relação ao seu sucesso em futuras tarefas da mesma natureza. Essas condições podem aumentar a tendência à ansiedade na performance. Músicos suscetíveis à ansiedade mal adaptativa na performance tem frequentemente atribuído o fracasso a causas internas (como a falta de esforço ou pouca prática) (PAPAGEORGI, 2007).

\section{Desenvolvimento insuficiente das habilidades metacognitivas}

A metacognição é caracterizada como o uso do raciocínio, razão e habilidades de aprendizado (McCOMBS, 2001), a definição de metas, resolução de problemas e estratégias de autoavaliação para maximizar a realização do potencial de aprendizagem. No que diz respeito à performance musical, estratégias metacognitivas empregadas por músicos incluem planejamento, monitoramento e avaliação do processo de aprendizado e da performance. A preparação para a performance requer que o performer dê prioridade à prática para ativar seu interesse na performance em questão e em gerenciar a ansiedade na performance. Isso depende do desenvolvimento de habilidades metacognitivas (HALLAM, 2002).

\section{Experiência de performance limitada}

Salmon e Meyer (1998) sugerem que uma razão possível para que performers experientes pareçam dominar a ansiedade mais facilmente é que o sentimento de estarem emocionalmente "prontos" antes e durante a performance é interpretado de forma diferente. Artistas experientes, devido à exposição frequente às situações performativas, podem sentir menos amedrontamento em relação à percepção da excitação fisiológica, já que eles aprenderam a esperar por essa excitação. Salmon, Schrodt e Wright (1989) sugerem que performers experientes aprendem a deixar seus picos de excitação acentuados imediatamente antes da performance, enquanto performers inexperientes sofrem de ansiedade pré-performance, que cresce durante um período de tempo e alcança seu pico durante a performance. A ansiedade que tem seu pico durante a performance geralmente traz efeitos prejudiciais, enquanto a excitação cujo ápice ocorre imediatamente antes da performance de uma determinada tarefa pode servir de preparação para alcançar as demandas de tal tarefa (WILSON, 2002).

\section{Experiências anteriores}

De acordo com Spielberger, Gonzalez, Taylor, Algaze e Anton (1978), a avaliação de uma situação como ameaçadora depende das características de seus estímulos, as experiências anteriores do indivíduo com situações análogas e as memórias ou pensamentos que são evocados ou reestimulados pela situação. Um indivíduo que vivenciou uma performance ruim e humilhante irá temer outra performance com o medo de falhar 
novamente (HARRIS, 1986). Por outro lado, experiências positivas anteriores podem trazer confiança ao performer (HANLEY, 1984).

\section{Estresse ocupacional}

O estresse ocupacional pode estar relacionado à ansiedade na performance. Há muitas fontes de estresse na vida de um músico. É comum que os músicos sejam mal pagos e estejam sob escrutínio do público e da crítica (RECINIELLO, 1991). A natureza altamente competitiva da profissão significa que eles frequentemente vivenciam a rejeição e a contínua pressão pode provocar insegurança (PHILIPPS, 1991). Steptoe (1989) sustenta a ideia de que os domínios do estresse na carreira e o medo de palco não são independentes e que estes devem ser considerados em conjunto uns com os outros na busca de um método abrangente para o gerenciamento do estresse em músicos profissionais. Os conceitos do estresse ocupacional e da ansiedade estão ligados, já que a ansiedade funciona de maneira a atrair a atenção para o estresse e as dificuldades da profissão de músico (STEPTOE, 2001).

\section{(ii) Fatores que influenciam a autoeficácia do performer}

A autoeficácia do performer parece ser influenciada pela quantidade de trabalho e compromisso que o músico coloca no processo da preparação para a próxima performance, a forma com que ele aprende e sua motivação. Isso está relacionado à dificuldade do repertório a ser tocado e às habilidades técnicas, musicais e de memorização do performer.

\section{Preparação inadequada}

A baixa eficácia de uma tarefa pode ser resultado de uma preparação inadequada ou certa incapacidade em dominar o repertório escolhido para a performance memorizada. ${ }^{10} \mathrm{O}$ baixo domínio sobre a tarefa na forma de uma preparação inadequada, falta de confiança em tocar de memória e a escolha de um repertório que excede a capacidade do indivíduo pode aumentar o medo de falhar e, consequentemente, a ansiedade na performance. Sweeney e Horan (1982) referiram-se à ansiedade como resultado de uma preparação prévia insuficiente chamada "ansiedade reativa", enquanto Lehrer (1995) indicou que não há nenhuma técnica psicológica que possa substituir uma preparação artística apropriada. Artistas precisam estar preparados para a performance através da prática e da preparação psicológica (LEHMANN, 1997). O performer deve planejar sua performance de acordo com suas capacidades e limitações. Se decidir realizar uma performance memorizada, é importante que esteja confiante, já que a insegurança pode aumentar seus níveis de ansiedade (HALLAM, 2003). O indivíduo deve usar o tempo de prática efetivamente para ajustar dedilhados, arcadas ou respiração, baseado no que ele sente ser mais confortável e no que possa minimizar as potenciais dificuldades técnicas no momento da performance e evitar um nervosismo adicional (HALLAM, 1992).

Abordagens de aprendizado superficiais

10 Memorização é um fator que mereceria ser investigado mais profundamente como gerador de APM (positiva ou negativa). Por outro lado, pesquisas (HALLAM, 2003) mostram que a performance memorizada pode transmitir mais segurança e domínio do performer, embora sujeita a lapsos de memória. 
Os métodos de aprendizado de um estudante têm impacto nos resultados e no sucesso das tarefas realizadas. Entwistle (1988) diferencia três abordagens de estudo, cujos nomes são: abordagem superficial, profunda e estratégica. Cada abordagem é distinguida por diferentes motivações e padrões de intenção da parte do aluno e tem resultados diferentes. Biggs (1988) propõe três orientações similares de aprendizado: a superficial, a profunda e a realizável. Estudantes superficiais são motivados predominantemente pelo desejo em completar o curso (ou tarefa), pois temem o fracasso. Sua intenção é simplesmente cumprir todos os requisitos de avaliação através da adoção de um aprendizado por repetição. Isso implica repetir e memorizar sem estar preocupado com um significado profundo. Essa abordagem reprodutiva é vista como relacionada à ansiedade de teste e fracasso (BIGGS, 1984). Estudantes superficiais ${ }^{11}$ têm medo de falhar, possuem muito pouca autoconfiança e adotam estratégias que não permitem alcançar um nível profundo de compreensão. No contexto da APM, indivíduos de "aprendizagem superficial" são supostamente mais propensos a experimentar a ansiedade mal adaptativa na performance.

\section{Motivação para a realização relacionada com o medo do fracasso}

Outro elemento considerado sob a eficácia da tarefa é a motivação, que pode desempenhar um papel significativo na preservação do interesse na performance. A motivação para se envolver nas atividades musicais é determinada por complexas interações entre o performer como indivíduo (suas características, autoconceito e metas) e o ambiente no qual se encontra (incluindo fatores culturais e históricos, ambiente educacional e o apoio que obtêm de sua família e companheiros) (HALLAM, 2002). A motivação para continuar envolvido no aprendizado de um instrumento é relacionada com o ambiente social e cultural, e é importante considerar como os pais e, em particular, o professor podem influenciar na motivação (O'NEILL; McPHERSON, 2002). A motivação para a realização é muito importante. A teoria da motivação para a realização (ATKINSON, 1964; ATKINSON; FEATHER, 1966) propõe que todos os indivíduos possuem um motivo para buscar se aproximar do sucesso (necessidade de realização) e ao mesmo tempo evitar o fracasso (medo de fracassar). O medo de uma avaliação negativa também está associado à APM (LEHRER, 1987). No contexto da performance musical, a motivação para a realização de uma pessoa pode estar relacionada à sua vulnerabilidade para a ansiedade, aos objetivos que persegue e ao esforço colocado para a sua preparação.

\section{Tarefas de grande dificuldade e valor}

A dificuldade percebida de uma peça, exame ou concerto influencia as expectativas de sucesso de uma pessoa, em conjunto com a adequação de sua preparação. Avaliações sobre uma elevada autoeficácia são importantes, considerando que podem estar relacionadas à confiança, à motivação e ao esforço investido (PAPAGEORGI, 2007).

\footnotetext{
11 Segundo Gomes (2010), são quatro os perfis de estudantes: profundos (alta AP e baixa AS), superficiais (baixa Aprendizagem Profunda - AP e alta Aprendizagem Superficial - AS), estratégicos (alta AP e alta AS) e não estratégicos (baixa AP e baixa AS) (GOMES, C. Perfis de estudantes e a relação entre abordagens de aprendizagem e rendimento escolar. Psico, Porto Alegre, v. 41, n. 4, p. 503-509, out./dez. 2010).
} 
Quando o indivíduo acredita que possui capacidade para completar uma tarefa difícil com sucesso, então o evento é visto como um desafio capaz de aumentar a motivação. Porém, quando uma tarefa é considerada acima da capacidade deste indivíduo e quando nenhum recurso para completá-la com sucesso está disponível, cria-se ansiedade, e a motivação diminui.

Quando um artista se compromete com uma performance em particular, ele faz sua avaliação não apenas em relação à dificuldade, mas também em relação ao valor e importância daquela performance. O valor subjetivo é uma combinação de uma avaliação subjetiva sobre a importância deste teste/performance, da utilidade do seu valor para alcançar objetivos futuros e seu interesse intrínseco na tarefa. Quando o valor subjetivo ou a importância ligada a uma performance ou teste é alta, a probabilidade de sentir altos níveis de ansiedade cresce (PEKRUN, 1984, 1985).

\section{Estratégias para lidar com a ansiedade}

As estratégias que os músicos utilizam para lidar com a ansiedade podem ser importantes para o sucesso do controle psicológico de sua excitação e alívio de um possível efeito mal adaptativo da ansiedade. Pesquisas indicam que estudantes que sentem ansiedade adaptativa na performance usam uma combinação de estratégias focadas em uma preparação adequada e uma atitude positiva em relação à performance, concentrando-se na comunicação com o público e na apreciação da música (PAPAGEORGI, 2007).

\section{(iii) Fatores relacionados ao ambiente da performance}

As características do ambiente onde o indivíduo irá tocar também desempenham um papel na promoção ou redução da ansiedade, já que a presença do público, o grau da perceptível autoexposição e as características do lugar são variáveis significativas.

\section{A presença do público}

A teoria de ansiedade na performance musical ${ }^{12}$ proposta por LeBlanc (1994) se refere à presença e ao comportamento do público como uma variável. Estudos empíricos no campo da música confirmaram que a presença do público frequentemente aumenta a ansiedade nos artistas (ABEL; LARKIN, 1990; FREDRIKSON; GUNNARSSON, 1992; HAMANN, 1982; LEGLAR, 1978).

\section{A percepção de autoexposição elevada}

Quanto mais exposto o performer se sente, no sentido de estar vulnerável durante a performance, maior é a chance de se sentir ansioso (WILSON, 1997). A sensação de exposição está relacionada a fatores como performances solo ou em grupo, performances em público ou práticas solitárias, performances avaliativas (exames, testes, 
audições, concursos de admissão etc.) em oposição a tocar por prazer em ambientes tranquilos ou, por fim, tocar peças difíceis ou com uma preparação musical inadequada ao invés de peças fáceis ou já bem estudadas pelo artista (WILSON, 1997). Resultados de pesquisas demonstram o aumento da ansiedade com a presença de colegas e críticos em performances solo e em pequenas orquestras, em oposição às grandes orquestras (BROTONS, 1994; FISHBEIN et al., 1988; GUSTAFSON; RAWSON, 1983; LEGLAR, 1978).

\section{Condições insatisfatórias para a performance}

Quaisquer condições que possam impedir o performer de agir com naturalidade, como desconforto físico no ambiente de performance ou no contexto, são consideradas impedimentos inesperados e obstáculos na performance, além de aumentar a preocupação e a ansiedade do músico. Parasuraman e Purohit (2000), por exemplo, constataram que uma das maiores fontes de estresse entre os músicos está relacionada ao ambiente de trabalho e inclui problemas como a qualidade do ar, a umidade, o conforto do assento e a legibilidade da partitura musical.

\section{Os efeitos da ansiedade na performance musical}

Como visto acima, a ontogênese da ansiedade na performance encontra-se na suscetibilidade individual, na eficácia da tarefa e em fatores relacionados ao ambiente da performance. Com relação à performance em si mesma, a ansiedade se manifesta geralmente de duas formas características: pode ter efeitos facilitadores (adaptativos) ou debilitantes (mal adaptativos). A ansiedade adaptativa é vista como facilitadora para o crescimento na performance através da preparação individual para a tarefa a ser realizada e pelo estímulo à concentração e atenção (GATES; MONTALBO, 1987; HAMANN, 1982; KEMP, 1996). Por outro lado, a ansiedade mal adaptativa é considerada prejudicial à performance. Seus efeitos podem variar desde pequenos deslizes até a deterioração de uma performance bem preparada (GABRIELSSON, 1999; LEHRER, 1987; STEPTOE, 2001).

Muitas teorias que relacionam ansiedade e excitação psicológica com a eficácia na performance têm sido desenvolvidas. A excitação psicológica se refere a um estado de atividade psicológica elevado, que está relacionado à ativação do sistema nervoso autônomo. Talvez a mais conhecida seja a Lei de Yerkes-Dodson ${ }^{13}$ (YERKES; DODSON, 1908), que é uma das primeiras afirmações baseadas em experimentos no que concerne à relação entre dirigir e aprender (LEVITT, 1968). A Lei de Yerkes-Dodson afirma principalmente que a excitação em grau muito elevado ou muito baixo não aumentam a qualidade da performance. Consequentemente, acredita-se que a qualidade máxima da performance está em níveis de excitação medianos. De acordo com Wilson (2002, p. 211), a lei afirma que "a excitação melhora a performance até certo ponto, para além do qual causará deterioração". A deterioração acontece mais rapidamente se a tarefa a ser realizada é complexa ou no caso de preparação insuficiente (WILSON, 2002). A 
lei sugere que o ápice da performance acontecerá sob um nível médio de excitação, enquanto níveis muito baixos ou muito altos resultarão em uma performance ruim. Steptoe (1983) levantou evidências para dar suporte à lei do $U$ invertido em termos de tensão e performance musical para estudantes e músicos profissionais. Ele observou que as melhores performances ocorriam em níveis moderados de tensão, apesar de o nível considerado "moderado" ter sido mais alto para profissionais do que para estudantes, concluindo-se que os profissionais normalmente podem lidar melhor com níveis de ansiedade elevados.

Wilson $(1973,1997,2002)$, na tentativa de desenvolver um modelo que mostrasse a relação da interação das variáveis da APM, elaborou e expandiu a relação de Yerkes-Dodson. Ele sugeriu que a excitação e os níveis de ansiedade dependem da interação entre três variáveis: a ansiedade-traço do performer, a dificuldade da tarefa e o grau predominante de estresse da situação.

Uma alternativa à lei de Yerkes-Dodson é a teoria da catástrofe (HARDY; PARFITT, 1991). De acordo com essa teoria, uma vez que o performer pode sentir um desastre iminente em uma situação de alto estresse e competitividade, o dano à performance é rápido e abrupto, ao invés de gradual, como sugere a curva do $U$ invertido. $O$ efeito catastrófico, de acordo com a teoria, é mais intenso quando ambas as ansiedades, cognitiva e fisiológica, estão altas. $O$ tradicional desenho do $U$ invertido proposto por Yerkes e Dodson só é aplicado quando a ansiedade cognitiva está baixa.

\section{Apresentação de um modelo conceitual}

Wilson $(1973,1997,2002)$ sugere que a excitação e os níveis de ansiedade dependem da interação entre ansiedade-traço, a dificuldade da tarefa e o provável grau de estresse da situação, mas poucas pesquisas têm investigado como estes fatores podem interagir para aumentar ou diminuir os níveis de ansiedade ou excitação ao longo do tempo. A ansiedade na performance musical tem sido considerada muito mais um evento isolado do que um processo que se desdobra antes, durante e depois da performance, apesar de Hallam (1998) e LeBlanc (1994) haverem desenvolvido modelos multidimensionais que descrevem as formas com que os fatores afetam o desenvolvimento da ansiedade na performance no período que a precede. $O$ modelo conceitual aqui apresentado desenvolve mais essas várias perspectivas e oferece uma descrição mais detalhada dos vários fatores e processos que podem afetar a performance em um contexto específico. Aumentar a compreensão sobre como a ansiedade na performance musical se desenvolve antes e durante a performance pode nos possibilitar encontrar maneiras mais efetivas de ajudar os artistas a administrarem sua ansiedade de maneira que ela não se torne um obstáculo na busca por uma carreira musical de sucesso.

A Figura 1 mostra o quadro de representação das interações desses fatores que podem afetar o músico desde o momento que se compromete com a performance, através da sua preparação, à performance em si e ao impacto dos resultados percebidos nos ciclos de preparação subsequentes. O quadro de hipóteses é dividido em três fases principais, com oito subfases que são representadas por números no lado esquerdo da 
figura. A numeração ascendente das subfases representa a passagem do tempo. O grupo de cor cinza claro apresenta as condições da pré-performance, o cinza médio representa as condições durante a performance e o cinza escuro as condições pós-performance. As caixas retangulares dentro da figura representam os diferentes estados da fase, e as setas significam progressões de uma caixa para outra. Elas denotam as condições que resultam no reposicionamento do performer através das fases de um estado para outro. As linhas pontilhadas indicam os efeitos adversos no performer e como as experiências prévias podem influenciar na vulnerabilidade do indivíduo à ansiedade no futuro.

No centro do modelo conceitual proposto estão os conceitos de formas adaptativas e mal adaptativas de ansiedade e a forma como a excitação sentida antes da performance pode ser debilitante ou facilitadora. Quando a ansiedade resulta em níveis elevados de excitação que não são percebidos como sendo controlados pelo performer, ela pode trazer consequências negativas em relação à qualidade da performance. Contudo, quando a ansiedade é controlada, ela pode servir para a preparação da ação, objetivando concentração e foco na tarefa. O modelo é baseado no pressuposto de que a ansiedade na performance musical não é um fenômeno estático, mas a conclusão de uma combinação de resultados de fatores e processos que são iniciados muito antes do evento atual, alguns dos quais derivam de características pessoais do indivíduo. Esses são trazidos para o cenário da performance e interagem com o ambiente performativo. As interações ocorrem durante a performance real, contribuindo para a natureza potencialmente volátil do resultado da mesma. Quando o evento chega ao fim, o parecer e autoavaliações da pós-performance criam novos relacionamentos ou estendem relacionamentos anteriores para performances subsequentes. O modelo sugere que a ansiedade na performance musical é uma construção multidimensional. Como mencionado anteriormente, a forma com que um performer avalia um evento depende tanto de suas características (que determinam o grau de vulnerabilidade à ansiedade) e de parâmetros mais situacionais quanto da eficácia da tarefa e da natureza do ambiente da performance. Esses três grupos de fatores influenciam a cognição do músico e o nível de excitação antes e durante a performance, o que, por sua vez, afeta o seu resultado: 


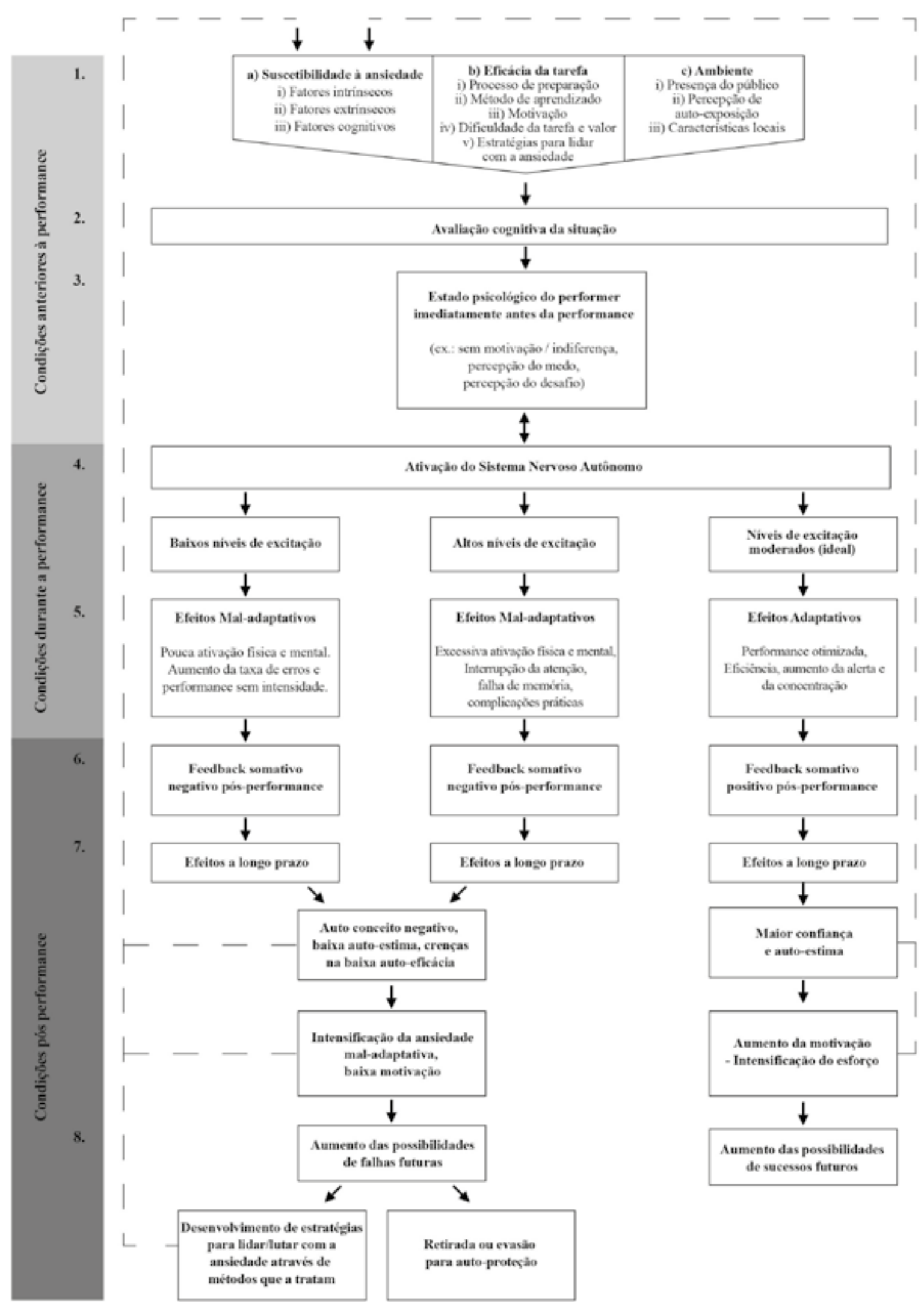

Fig. 1 - Modelo conceitual sobre a ansiedade na performance musical 


\section{Descrição do modelo conceitual}

A descrição do modelo conceitual desenvolvido progride em relação ao alinhamento de noção do tempo, começando da subfase 1 à subfase 8 . Os elementos que compõem cada subfase são introduzidos, e as evidências da literatura relacionada são apresentadas e discutidas no contexto da performance musical.

\section{Fase 1: Condições da pré-performance}

\section{Subfase 1: Condições iniciais}

O processo se inicia na subfase 1, que contém três importantes elementos: (a) a predisposição do performer em vivenciar a ansiedade quando o compromisso com a performance é assumido, (b) a eficácia do performer para realizar a tarefa, e (c) as características específicas do ambiente onde o indivíduo irá tocar. Essas três condições iniciais são relatadas no modelo tridimensional de ansiedade de Wilson (WILSON, 1973, 1997, 2002). O autor acredita que o nível de ansiedade na performance depende da interação entre ansiedade-traço, dificuldade da tarefa e estresse situacional. O modelo apresentado aqui pode ser visto como elaboração e extensão do modelo de Wilson. As condições que ele estabelece são mais explicitamente definidas aqui, e mais variáveis são incluídas. A predisposição à ansiedade não é solidamente definida em termos de ansiedade-traço, mas é considerada uma variável multidimensional determinada por fatores intrínsecos, extrínsecos e cognitivos. A ansiedade-traço é conceitualizada como uma característica intrínseca do performer. A eficácia de uma tarefa é um termo mais amplo usado neste contexto para explicar até que ponto o artista está preparado para completar a performance com sucesso. Isto inclui o processo de preparação, métodos de aprendizado, motivação e a dificuldade da tarefa. As características do ambiente da performance são cruciais para determinar como o performer irá avaliar o evento. Elas são determinadas pela presença do público, pela percepção do grau de autoexposição e pelas características do local onde a performance irá ocorrer. Pressupõe-se que essas três primeiras condições determinam como o evento da performance é inicialmente avaliado pelo músico. O modelo leva em conta os efeitos da ansiedade em curto prazo (na qualidade da performance) e a longo prazo (sobre a confiança e motivação do artista no futuro). Ele é projetado para explicar como os efeitos da ansiedade no intérprete, a longo prazo, podem influenciar sua vulnerabilidade à ansiedade no futuro e, assim, mudar sua posição inicial dentro do modelo.

As interações entre os três elementos definem a qualidade da avaliação cognitiva do intérprete em relação à performance e seu estado psicológico imediatamente antes do evento. Por exemplo, quando um músico com uma predisposição elevada à ansiedade, e que tem uma percepção de baixa eficácia em uma tarefa, é solicitado a tocar em um ambiente amedrontador e/ou desconfortável, provavelmente ele irá perceber a situação da performance como ameaçadora e ficará muito ansioso. Por outro lado, a baixa predisposição à ansiedade em combinação com a autoeficácia alta da tarefa e um ambiente não ameaçador ou pouco ameaçador irão, provavelmente, aumentar a motivação para o sucesso e a confiança em manter a ansiedade em níveis razoáveis. 


\section{Subfase 2: Avaliação cognitiva da situação}

Todos os elementos citados anteriormente determinam a avaliação cognitiva da performance e o estado psicológico do músico, exibido no diagrama da subfase 2 , como indicado pelas setas. A avaliação cognitiva é um processo cognitivo de apreensão e interpretação que medeia o ambiente e as reações emocionais do músico (LAZARUS, 1991; LAZARUS; FOLKMAN, 1984). De acordo com Lazarus (1991), existem duas maneiras de avaliação do processo: primária e secundária. A avaliação primária refere-se ao processo de perceber e avaliar a situação. Exemplos de tais avaliações podem incluir a ameaça, o desafio, prejuízos ou benefícios a si mesmo. A avaliação secundária vem sob a forma de julgamentos relativos às formas de enfrentamento disponíveis para dominar o potencial dano ou ameaça ou para facilitar os possíveis benefícios. Dependendo da análise e da avaliação subjetiva das formas de enfrentamento disponíveis, o intérprete terá uma reação emocional particular imediatamente antes de se apresentar. A qualidade do estado psicológico é o resultado direto de uma interação entre esses dois estágios de avaliação.

Subfase 3: O estado psicológico do performer imediatamente antes da performance

A avaliação cognitiva da performance irá estimular uma reação emocional específica e desencadeará um estado afetivo como resultado para a percepção do artista. Isto é mostrado na subfase 3 do modelo. A falta de motivação ou um estado de relativa indiferença será desencadeado se o performer julgar que o evento não é importante para ele ou que não há interesse em se sair bem. A percepção da ameaça é outra possibilidade na avaliação da situação pelo músico; se o artista conclui que tem recursos insuficientes para trabalhar, ele estará mais propenso a não se sair bem. Isso aumentará a ansiedade. Por outro lado, a percepção da tarefa como desafiadora, mas não além das capacidades do intérprete, pode funcionar como motivação para que o performer queira se esforçar para sair bem. O nível do desafio afetará o quanto o músico se sentirá motivado para maximizar seus esforços para a performance em questão. Teorias da motivação indicam que, quando o desafio está em equilíbrio com as habilidades da pessoa, o indivíduo coloca prazer e tenderá a querer continuar desempenhando aquela tarefa. Atividades deste tipo são aquelas que têm uma motivação intrínseca (GOOD; BROPHY, 1991). Se a tarefa é muito fácil para a pessoa, ela pode se sentir entediada, indiferente e desmotivada. Quando a tarefa excede as habilidades do indivíduo, ou se a pessoa acredita que a tarefa é muito difícil para ela, há pouca chance de desempenhá-la bem (mesmo que isto não seja o objetivo nesse caso) e podem ocorrer altos níveis de ansiedade (HALLAM, 2002).

\section{Fase 2: Condições durante a performance}

\section{Subfase 4: Ativação do Sistema Nervoso Autônomo}

O performer interpreta uma peça musical em um estado psicológico e emocional específico. A Subfase 4 demonstra que o Sistema Nervoso Autônomo (SNA) é ativado de modo a preparar o músico para lidar com a tarefa (tocar um instrumento musical) 
sob as circunstâncias específicas da performance. Isso está relacionado a níveis baixos, médios e altos de excitação. O termo excitação é utilizado aqui no sentido de ativação psicológica. Como mencionado acima, existe uma hipótese de que pouca ou muita excitação não é "ideal", enquanto um nível médio de excitação tem um efeito positivo, que desencadeia uma "excitação ideal" (YERKES; DODSON, 1908). Alguns estudos na área da música apoiam a relação do $U$ invertido entre excitação e eficiência da performance (HAMANN, 1982; HAMANN; SOBAJE, 1983; LEGLAR, 1978). O que constitui a "excitação ideal" para qualquer indivíduo é muito difícil de ser estabelecido, e a relação mediadora das variáveis das diferenças individuais e a dificuldade da tarefa podem ser importantes. Isso significa que a excitação ideal pode variar, não somente entre pessoas diferentes, mas também na mesma pessoa sob diferentes condições.

A flecha com duas pontas entre os níveis 3 e 4, além de mostrar o estado afetivo do performer, está relacionada ao Sistema Nervoso Autônomo e também indica que é possível que a percepção da ativação do SNA e a excitação somática possam ser as causas para mais sofrimento psicológico. Isto ocorre porque, em um alto grau de excitação, as pessoas tendem a detectar eventos que poderiam, em outra situação, escapar desapercebidas (SALMON; MEYER, 1998). A ansiedade também pode, portanto, aumentar a consciência das sensações internas. Os sintomas fisiológicos da ansiedade são percebidos como amplificados em magnitude e sua gravidade é exagerada na mente do artista (SALMON; MEYER, 1998). Isso pode causar pânico aos performers, especialmente naqueles menos experientes e não acostumados a estas sensações, e aumentar mais os níveis de ansiedade se os artistas sentem que esses sintomas psicológicos irão interferir em sua habilidade para tocar bem.

Subfase 5: Efeitos dos níveis de excitação na qualidade da performance

A Subfase $5^{14}$ mostra os efeitos de cada estado de excitação na qualidade da performance. Diferentemente de níveis de excitação ideais, níveis muito baixos ou muito altos levam, em hipótese, a efeitos mal adaptativos (negativos), enquanto níveis de excitação ideais (médios) resultam em efeitos adaptativos (positivos). A excitação muito baixa pode resultar numa ativação física e mental pobre ou em letargia. Por outro lado, níveis de excitação altos podem resultar numa ativação mental e física excessiva, parte devido a uma percepção aguçada dos sintomas de excitação fisiológica que pode causar pânico ao performer. A excitação média é, em hipótese, o nível mais próximo do ideal, já que, quando ela é mantida sob controle, pode melhorar a eficiência da performance, a prontidão e a concentração do artista para a tarefa (GATES; MONTALBO, 1987; HAMANN, 1982; KEMP, 1996; WILSON; ROLAND, 2002), e assim aumenta as possibilidades de resultados positivos, caso o músico esteja adequadamente preparado e se sinta confiante. 


\section{Fase 3: Condições pós-performance}

Subfase 6: Feedback pós-performance

O feedback para a qualidade da performance (não importa se interpessoal ou intrapessoal) após o evento influencia o método do performer em futuras apresentações (HALLAM, 2003) e pode, assim, ter um papel significativo na ansiedade subsequente. $O$ feedback, neste caso, significa o que está fora do momento-a-momento proprioceptivo, e feedback auditivo o que é parte integrante da performance musical à medida que se desenrola. O feedback é tanto interno (auto monitoramento) quanto externo (vem de fora do performer). Ele também pode ser considerado como "sumativo", no sentido de que acontece após a performance. A Subfase 6 ilustra os resultados possíveis. Onde a performance foi considerada de sucesso, é provável que um feedback positivo sumativo seja assegurado. Isto pode se transformar em uma avaliação formal (por exemplo, através de notas em uma prova), no recebimento de comentários positivos de outras pessoas, de automonitoramento avaliativo ou a combinação de todos os fatores. $\mathrm{Na}$ ausência de um feedback externo, existe a possibilidade de um "reforço subjetivo" no qual o performer constrói sua própria versão da qualidade de seu comportamento e faz uso disto para enquadrar sua futura conduta (WELCH, 1985). Onde a performance é caracterizada por erros e fracassos, o feedback negativo será óbvio. Meyer $(1982,1983)$ considera o feedback emocional na performance e explica como isto pode influenciar a autopercepção de um indivíduo sobre suas próprias habilidades. Ele argumenta que um indivíduo pode perceber as emoções de outras pessoas e fazer inferências sobre como os outros percebem suas habilidades. Essas opiniões inferidas sobre a avaliação de terceiros também podem influenciar sua autoavaliação. Autopercepções de habilidades influenciam expectativas, emoções e comportamentos futuros. De acordo com Graham e Weiner (1983), um indivíduo irá empregar feedback emocional para avaliar sua própria habilidade, em especial se outros processos relativos à sua performance levarem a resultados ambíguos.

\section{Subfase 7: Efeitos de longo prazo}

A qualidade do feedback pós-performance, especialmente se vivida repetidamente ao longo de períodos de tempo, produzirá efeitos de longo prazo, como mostrado na Subfase 7. Se o feedback é negativo, existe grande chance de estimular a ansiedade em condições similares, com provavelmente o mesmo resultado negativo. Isso pode levar a percepções de um autoconceito negativo, baixa autoestima e crenças sobre sua baixa autoeficácia, possivelmente resultando numa intensificação da ansiedade na performance nas próximas apresentações, afetando negativamente os esforços e motivações de um indivíduo na tentativa de obter sucesso. Se o feedback é percebido como positivo, o performer (permitido por suas características individuais - ver sessão (i) em "fatores" acima) tenderá a experimentar um aumento na sua confiança e autoestima, criando pré-condições positivas de sucesso em performances análogas no futuro, as quais servirão para aumentar a motivação e intensificar seus esforços.

O sucesso e a atribuição de alta capacidade também podem contribuir para que 
o indivíduo crie um autoconceito positivo ao imaginar um "eu futuro positivo possível" nesse domínio (MARKUS; RUVOLO, 1989), o que pode aumentar a motivação que dará origem ao sucesso. Uma performance ruim pode levar a temer seu próprio self. $O$ recebimento e redirecionamento do feedback para o performer é ilustrado pela linha pontilhada que conecta as caixas do nível 7 com a predisposição do performer para a ansiedade na subfase 1a. A variação de um dos parâmetros na subfase 1 influenciará inevitavelmente a avaliação cognitiva do performer em uma apresentação subsequente e, consequentemente, também o seu estado psicológico inicial. Como resultado, a posição inicial do artista no modelo pode mudar em relação ao tempo. O modelo aqui proposto é dinâmico, os resultados podem mudar em relação aos múltiplos inputs e componentes.

Subfase 8: As possibilidades para futuro sucesso/fracasso e respostas

A Subfase 8 sugere que a intensificação da ansiedade mal adaptativa na performance e a motivação mais baixa resultam em um aumento nas possibilidades de experimentar fracasso nas performances futuras. Duas respostas comportamentais mais relevantes podem ser garantidas sobre o que foi dito acima, que tem similaridades com o mecanismo de resposta "lutar-ou-fugir": o desenvolvimento de uma gama de estratégias e a busca por um método para lidar com a ansiedade que seja apropriado com o objetivo de superar o problema (lutar) ou evitar ou desistir por motivos de autoproteção (fugir). Lutar ou fugir é uma resposta genética inata que é estimulada durante situações de ansiedade ou estresse (LEHRER, 1987). Lutar acontece quando o indivíduo decide confrontar o perigo potencial, e fugir acontece quando o indivíduo decide se afastar dos perigos. Esses comportamentos também podem aparecer após experiências de ansiedade em períodos prolongados de tempo. Por outro lado, caso o performer escolha evitar ou desistir da performance, então, a renúncia acontece (fuga). Se, por outro lado, o músico ansioso desenvolve estratégias para lidar com a situação e decide adotar um método para administrá-la (enfrentamento), é provável que isto influencie o grau de sua vulnerabilidade à ansiedade nas performances que se seguirem. Eles podem se sentir menos ansiosos e mais confiantes para as próximas situações, alterando assim sua posição inicial em relação ao modelo.

O lado direito do modelo indica que a motivação elevada e a intensificação dos esforços podem aumentar as possibilidades de sucesso no futuro, levando a efeitos positivos para o bem-estar do performer e sua autopercepção e diminuindo as possibilidades de sentir ansiedade mal adaptativa através da redução da vulnerabilidade à ansiedade em geral.

\section{Sumário, implicações e direções futuras}

Este artigo traz uma revisão da literatura existente focando numa grande variedade de fatores que vêm sendo associados com a ansiedade e seus efeitos na performance musical. A estimativa é de que $15 \%$ dos músicos sintam a ansiedade como um problema significativo (STEPTOE, 2001). Fatores contribuintes relativos às diferenças individuais 
que influenciam a suscetibilidade do músico a experimentar ansiedade durante a performance incluem características intrínsecas, extrínsecas e cognitivas. Os fatores contribuintes também estão relacionados à eficácia do performer em tarefas e no ambiente de atuação. A literatura existente indica que a ansiedade na performance pode ser concebida como primariamente adaptativa ou mal adaptativa. A excitação fisiológica parece ser um importante parâmetro para medir como a ansiedade na performance influencia a qualidade da apresentação. Esses têm sido os componentes básicos sobre os quais o modelo conceitual tem se desenvolvido. O modelo conceitual ilustra os processos que tomam lugar quando um músico concorda em participar de uma performance e mostra o desenvolvimento da ansiedade como um processo que se desdobra em uma sequência pré, durante e pós-performance. O modelo conceitual indica que a forma com que o performer avalia um evento depende de sua vulnerabilidade à ansiedade, sua autoeficácia e o ambiente no qual a performance irá acontecer. Esta avaliação, por sua vez, afeta o estado emocional e fisiológico do músico imediatamente antes da performance. O Sistema Nervoso Autônomo é ativado e, dependendo do nível de excitação e do controle que o performer tem sobre ele, pode-se experimentar efeitos adaptativos e mal adaptativos na qualidade de sua performance. O feedback subsequente à performance pode ter efeitos a longo prazo, particularmente se o performer tem uma maior visão holística de sua habilidade musical. Um feedback negativo pós-performance pode resultar em autocrenças negativas, intensificação da ansiedade mal adaptativa na performance musical e diminuição da motivação. Um feedback positivo pós-performance irá reforçar a confiança e a autoestima, aumentará a motivação, assim como as possibilidades de um sucesso futuro. Estes retornam ao músico, diminuindo sua suscetibilidade à ansiedade em performances futuras semelhantes.

O modelo proposto também fornece um quadro para pesquisas futuras, enfocando o processo e o tempo, bem como o impacto de fatores relacionados. Situa a APM em um contexto mais amplo extraído de teorias e pesquisas relacionadas à emoção, psicologia educacional, ansiedade social e ansiedade de teste. Pesquisas futuras podem considerar se diferentes níveis de "ansiedade ideal" existem para diferentes músicos, em que medida a idade é um fator (crianças, adolescentes, adultos), se o nível de expertise (estudantes, profissionais, amadores) é importante e se existem diferentes níveis de ativação de ansiedade mal adaptativa para diferentes músicos. Estudos longitudinais que visam a avaliar os efeitos da ansiedade no desempenho de músicos serão particularmente úteis, pois permitirão monitorizar mudanças na ansiedade na performance a médio e longo prazos. Adicionalmente, pesquisas que comparam ansiedade em músicos em diversas culturas musicais podem nos ajudar a entender como os contextos de aprendizagem são relacionados à ansiedade na performance.

Há uma série de implicações para a educação a partir do modelo conceitual. Primeiramente, a importância das características individuais em moldar a suscetibilidade à ansiedade deve ser levada em conta nos contextos educativos. Avaliar a vulnerabilidade dos alunos à ansiedade pode informar os professores de forma útil quando eles precisam modificar seus métodos e estratégias de ensino para atender às diferentes necessidades de cada aluno. O delineamento do processo da ansiedade (a natureza da ansiedade 
na performance ao longo do tempo) pode ajudar os estudantes e seus professores a entenderem como lidar melhor com a ansiedade em pontos diferentes do processo. Além disso, enquanto os alunos devem receber tarefas desafiadoras para manter a motivação, os professores devem se certificar de que estas se enquadram nas capacidades do aluno para não gerar mais ansiedade. Os professores devem prover feedbacks construtivos aos jovens músicos, assim, o desenvolvimento positivo e a autoconfiança são promovidos, e a motivação para o envolvimento musical não será comprometida. Os professores devem preservar o interesse dos alunos e a motivação intrínseca e ajudar a manter uma abordagem saudável e balanceada para a performance, tendo em conta que cada apresentação é uma experiência de aprendizado. A nível prático, professores precisam garantir que os alunos estejam familiarizados com o local da performance antes de o evento acontecer, assim, eles estarão psicologicamente preparados para o que se espera e para tocar. Os professores também precisam enfatizar a importância da comunicação musical e o prazer da performance pelo público. Além disso, eles devem enfatizar que certa ansiedade e excitação fisiológica antes da performance são naturais e, em alguns casos, necessárias para uma performance eficaz.

Por fim, uma compreensão profunda sobre os fatores que contribuem para a ansiedade na performance ajudará no seu controle. A conscientização é crucial no processo de aprendizado para lidar com a ansiedade de forma eficaz. Programas educativos não devem focar somente na preparação técnica da performance, mas também oferecer uma preparação psicológica e prover com feedback formativo quando possível. Os responsáveis pelas políticas públicas devem pensar na concepção de programas e seminários que abordem a ansiedade na performance como parte da educação de jovens músicos e ajudá-los no processo de aprender a lidar efetivamente com esse problema, encontrando formas de usar a excitação para melhorar o desempenho e para manter o bem-estar emocional.

\section{REFERÊNCIAS}

ABEL, J. L.; LARKIN, K. T. Anticipation of performance among musicians: physiological arousal, confidence, and state anxiety. Psychology of Music, v.18, n.2, p.171- 182, 1990.

ABRAMS, D.; MANSTEAD, A. S. A test of theories of social facilitation using a musical task. British Journal of Social Psychology, v.20, n.4, p.271-278, 1981.

ATKINSON, J. W. An introduction to motivation. Princeton, New Jersey: Van Nostrand, 1964.

ATKINSON, J. W.; FEATHER, N. T. A theory of achievement motivation. New York: Wiley, 1966.

BANDURA, A. Self-efficacy: Towards a unifying theory of behavior's therapy. Psychological Review, v.84, n.2, p.191-215, 1977. 
BANDURA, A. Self-efficacy mechanism in human agency. American Psychologist, v.37, n.2, p. 122-147, 1982.

BANDURA, A. Self-efficacy: The exercise of control. New York: W. H. Freeman and Company, 1997.

BIGSS, J. Approaches to learning and to essay writing. In: SCHMECK, R. R. (Ed.), Learning strategies and learning styles. New York: Plenum Press, p.185-228, 1988.

BIGSS, J. Learning strategies, student motivation patterns, and subjectively perceived success. In: KIRBY, J. R. (Ed.), Cognitive strategies and educational performance. Orlando, FL: Academic Press, p. 111-134, 1984.

BROTONS, M. Effects of performing conditions on music performance anxiety and performance quality. Journal of Music Therapy, v.31, n.1, p. 63-81, 1994.

COX, W.; J.; KENARDY, J. Performance anxiety, social phobia and setting effects in instrumental music students. Journal of Anxiety Disorders, v. 7, n. 1, p. 49-60, 1993.

DEWS, C. L. B.; WILLIAMS, M. S. Student musicians' personality styles, stresses, and coping patterns. Psychology of Music, v. 17, n. 1, p. 37-47, 1989.

DWECK, C. S. Self-theories: Their role in motivation, personality and development. Hove, UK: Psychology Press, 2000.

ENTWISTLE, N. Motivational factors in students' approaches to learning. In: SCHMECK, R. R. (Ed.), Learning strategies and learning styles. New York: Plenum Press, p. 21-51, 1988.

FISHBEIN, M. et al. Medical problems among ISCOM musicians: Overview of a national survey. Medical Problems of Performing Artists, v. 3, n.1, p. 1-8, 1988.

FREDRIKSON, M.; GUNNARSSON, R. Psychology of stage fright: The effects of public performance on neuroendocrine, cardiovascular and subjective reactions. Biological Psychology, v. 33, n. 1, p. 51-61, 1992.

GABRIELSSON, A. The performance of music. In: Deutsch, D. (Ed.), The psychology of music. San Diego: Academic Press, p. 501-602, 1999.

GATES, A. G.; MONTALBO, P. J. The effect of low-dose beta blockade on performance anxiety in singers. Journal of Voice, v. 1, n. 1, p. 105-108, 1987.

GOOD, T. L.; BROPHY, J. E. Educational psychology. New York: Longman, 1991. 
GRAHAM, S. H.; WEINER, B. Some educational implications of sympathy and anger from an attributional perspective. Unpublished paper. Los Angeles, University of California, LA, 1983.

GUSTAFSON, E; RAWSON, D. Rambfeber hos strakmusiker (Stage fright in string players). Unpublished Masters Thesis. Uppsala University, Uppsala, Sweden, 1983.

HALLAM, S. Approaches to learning and performance of expert and novice musicians. Unpublished PhD thesis. University of London, 1992.

HALLAM, S. Instrumental teaching: A practical guide to better teaching and learning. Oxford: Heinemann, 1998.

HALLAM, S. Musical motivation: Towards a model of synthesising the research. Music Education Research, v. 4, n. 2, p. 225-244, 2002.

HALLAM, S. Supporting students in learning to perform. In: HANKEN, I. M.; NIELSEN, S.G. ; NERLAND, M. (Eds.), Research in and for higher music education. Festschrift for Harald Jørgensen. Oslo: Norges musikkhøgskole, p. 23-44, 2003.

HAMANN, D. L. An assessment of anxiety in instrumental and vocal performances. Journal of Research in Music Education, v. 30, n. 2, p. 77-90, 1982.

HAMANN, D. L.; SOBAJE, M. Anxiety and the college musician: A study of performance conditions and subject variables. Psychology of Music, v. 11, n. 1, p. 37-50, 1983.

HANLEY, M. A. Creative visualisation: Antidote of performance anxiety? American Music Teacher, v. 33, n. 6, p. 28-29, 1984.

HARDY, L.; PARFITT, G. A catastrophe model of anxiety and performance. British Journal of Psychology, v. 82, n. 2, p. 163-178, 1991.

HONG, Y.; CHIU, C.; DWECK, C.S. Implicit theories, attributions, and coping: A meaning system approach. Journal of Personality and Social Psychology, v. 77, n. 3, p. 588599, 1999.

KEMP, A. E. The personality structure of the musician. I. Identifying a profile of traits for the performer. Psychology of Music, v. 9, n. 1, p. 3-14, 1981.

KEMP, A. E. The musical temperament: Psychology and personality of musicians. Oxford: Oxford University Press, 1996. 
KENNY, D. A systematic review of treatments for music performance anxiety. Anxiety, Stress and Coping, v. 18, n. 3, p. 183-208, 2005.

KENNY, D.; OSBORNE, M. S. Music performance anxiety: New insights from young musicians. Advances in Cognitive Psychology, v. 2, n. 2-3, p. 103-112, 2006.

KLEINKNECHT, R. A. Mastering anxiety: The nature and treatment of anxious conditions. New York: Plenum Press, 1991.

LAZARUS, R. S. Emotion and adaptation. Oxford: Oxford University Press, 1991.

LAZARUS, R. S.; FOLKMAN, S. Stress, appraisal and coping. New York: Springer, 1984.

LEBLANC, ALBERT. A theory of music performance anxiety. The Quarterly Journal of Music Teaching and Learning, v. 5, n. 4, p. 60-68, 1994.

LEBLANC, A. et al. Effect of audience on music performance anxiety. Journal of Research in Music Education, v. 45, n. 3, p. 480-496, 1997.

LEGLAR, M. P. Measurement of indicators of anxiety levels under varying conditions of musical performance. Dissertations Abstracts International, 39, 5201A-5202A, 1978.

LEHMANN, A. C. The acquisition of expertise in music: Efficiency of deliberate practice as a moderating variable in accounting for sub-expert performance. In: DELIĖGE, l; SLOBODA, J. (Eds.), Perception and cognition of music. Hove: Psychology Press, p. 161-187, 1997.

LEHRER, P. M. A review of the approaches to the management of tension and stage fright in music performance. Journal of Research in Music Education, v. 35, n. 3, p.143153, 1987.

LEHRER, P. M. Performance anxiety and how to control it: A psychologist's perspective. In: GRINDEA, C. (Ed.), Tensions in the performance of music. London: Kahn \& Averill, p. 134-152, 1995.

LEHRER, P. M.; GOLDMAN, N. S.; STROMMEN, E. F. A principal components assessment of performance anxiety among musicians. Medical Problems of Performing Artists, v. 5, n. 1, p. 12-18, 1990.

LEVITT, E. E. The psychology of anxiety. London: Staples Press, 1968.

MAGNUSSON, D.; STATTIN, H. Situation-outcome contingencies: A conceptual and empirical analysis of threatening situations. Report from the Department of Psychology, University of Stockholm, 1981. 
MARKUS, H.; RUVOLO, A. Possible selves: Personalised representations of goals. In: PERVIN, L. A. (Ed.), Goal concepts in personality and social psychology. Hillsdale, NJ: Lawrence Erlbaum Associates, p. 211-241, 1989.

MCCOMBS, B.L. Self-regulated learning and academic achievement: A phenomenological view. In: ZIMMERMAN, B. J.; SCHUNK, D. H. (Eds.), Self-regulated learning and academic achievement. Lawrence Erlbaum Associates, p. 67-123, 2001.

MCCORMICK, J.; MCPHERSON, G. E. The role of self-efficacy in a musical performance examination: An exploratory structural equation analysis. Psychology of Music, v. 31, $n$. 1, p. 37-51, 2003.

MCPHERSON, G.E.; MCCORMICK, J. Motivational and self-regulated learning components of musical practice. Bulletin of the Council for Research in Music Education, $n$. 141, p. 98-102, 1999.

MCPHERSON, G. E.; MCCORMICK, J. Self-efficacy and music performance. Psychology of Music, v. 34, n. 3, p. 322-336, 2006.

MEYER, W. U. Indirect communications about perceived ability estimates. Journal of Educational Psychology, v. 74, n. 6, p. 888-897, 1982.

MEYER, W. U. Prozesse der Selbstbeurteilung: Das Konzept von den eigenen Begabung. Zeitschrift für Entwicklungspsychologie und Pädagogische Psychologie, v. 15, n. 1, p. 1-25, 1983.

MOR, S.et al. Perfectionism, control and components of performance anxiety in professional artists. Cognitive Therapy and Research, v. 19, n. 2, p. 207-225, 1995.

O'NEILL, S. A. The self-identity of young musicians. In: MACDONALD, R.; HARGREAVES, D.; MIELL, D. (Eds.), Musical Identities. Oxford: Oxford University Press, p. 79-96, 2002.

O'NEILL, S. A.; MCPHERSON, G. E. Motivation. In: PARNCUTT, R.; MCPHERSON, G. E. (Eds.), The science and psychology of music performance: Creative strategies for teaching and learning. New York: Oxford University Press, p. 31-46, 2002.

PAPAGEORGI, I. Understanding performance anxiety in the adolescent musician. Tese de Doutorado. Institute of Education, University of London, 2007.

PARASURAMAN, S.; PUROHIT, Y. S. Distress and boredom among orchestral musicians: The two faces of stress. Journal of Occupational Health Psychology, v. 5, n. 1, p. 74-83, 2000. 
PEKRUN, R. An expectancy-value model of anxiety. In: H. M. VAN DER PLOEG, H. M.; SCHWARZER, R.; SPIELBERGER, C. D. (Eds.), Advances in test anxiety research. Lisse, The Netherlands: Swets \& Zeitlinger, v.3, p. 53-72, 1984.

PEKRUN, R. Classroom climate and test anxiety: Developmental validity of expectancyvalue theory of anxiety. In: H. M. VAN DER PLOEG, H. M.; SCHWARZER, R.; SPIELBERGER, C. D. (Eds.), Advances in test anxiety research. Lisse, The Netherlands: Swets \& Zeitlinger, v. 4, p. 147-158, 1985.

PHILLIPS, E. M. Acting as an insecure occupation: The flipside of stardom. In:WILSON, G. D. (Ed.), Psychology and performing arts. Amsterdam: Swets \& Zeitlinger, p. 133-142, 1991.

PRUETT, K. D. Psychological aspects of the development of exceptional young performers and prodigies. In: SATALOFF, R. T.; BRANDFONBRENER, A. G.; LEDERMAN, R. J. (Eds.), Textbook of performing arts medicine. New York: Raven Press, p. 337-349, 1991.

RAE, G.; MCCAMBRIDGE, K. Correlates of performance anxiety in practical music exams. Psychology of Music, v. 32, n. 4, p. 432-439, 2004.

RECINIELLO, S. Towards an understanding of the performing artist. In: WILSON, G. D. (Ed.), Psychology and performing arts. Amsterdam: Swets \& Zeitlinger, 1991.

REUBART, D. Anxiety and musical performance: On playing the piano from memory. New York: Da Capo Press, 1985.

RYAN, C. Gender differences in children's experience of musical performance anxiety, v. 32, n. 1, p. 89-103, 2004.

SALMON, P. G.; MEYER, R. G. Notes from the Green Room: Coping with stress and anxiety in musical performance. San Francisco: Jossey-Bass, 1998.

SALMON, P.; SCHRODT, R.; WRIGHT, J. A temporal gradient of anxiety in a stressful performance context. Medical Problems of Performing Artists, v. 4, n. 2, p. 77-80, 1989.

SCHULZ, W. Analysis of a symphony orchestra. In: Piperek, M. (Ed.), Stress and music: Medical, psychological, sociological, and legal strain factors in a symphony orchestra musicians profession. Vienna: Wilhelm Braumuller, p. 35-56, 1981.

SCHWARZER, R.; JERUSALEM, M. Advances in anxiety theory: A cognitive process approach. In: HAGTVET, K. A.; JOHNSEN, B. T. (Eds.), Advances in test anxiety research. The Netherlands: Swets \& Zeitlinger, v. 7, p. 2-17, 1992. 
SPIELBERGER, C.et al. Examination stress and test anxiety. In: SPIELBERGER, C. D.; SARASON, I. G. (Eds.), Stress and anxiety. Hemisphere, v.5, p. 167-191, 1978.

STEPTOE, A. The relationship between tension and the quality of musical performance. Journal of the International Society for the Study of Tension in Performance, v. 1, $n$. 1, p. $12-22,1983$.

STEPTOE, A. Stress, coping and stage fright in professional musicians. Psychology of Music, v. 17, n. 1, p. 3-11, 1989.

STEPTOE, A. Negative emotions in music making: The problem of performance anxiety. In: JUSLIN, P. N.; SLOBODA, J. A. (Eds.), Music and emotion: Theory and research. Oxford: Oxford University Press, p. 291-307, 2001.

SWEENEY, G. A.; HORAN, J. J. Separate and combined effects of cue-controlled relaxation and cognitive restructuring in the treatment of musical performance anxiety. Journal of Counselling Psychology, v. 29, n. 5, p. 486-497, 1982.

TOBACYK, J. J.; DOWNS, A. Personal construct threat and irrational beliefs as cognitive predictors of increases in musical performance anxiety. Journal of Personality and Social Psychology, v. 51, n. 4, p. 779-782, 1986.

VALENTINE, E. The fear of performance. In: Rink, J. (Ed.), Musical performance: A guide to understanding. Cambridge: Cambridge University Press, p. 168-182, 2002.

WEINER, B. An attributional theory of achievement motivation. Psychological Review, v. 92, n. 4 , p. $548-573,1985$.

WELCH, G. F. A schema theory of how children learn to sing in tune. Psychology of Music, v. 13, n. 1, p. 3-18, 1985.

WILLIAMON, A. (Ed.). Musical excellence: Strategies and techniques to enhance performance. Oxford: Oxford University Press, 2004.

WILSON, G. D. Abnormalities in motivation. In: EYSENCK, H. J. (Ed.), Handbook of abnormal psychology. London: Pitman Medical, p. 362-389, 1973.

WILSON, G. D. Performance anxiety. In: HARGREAVES, D. J.; NORTH, A. C. (Eds.), The social psychology of music. Oxford: Oxford University Press, p. 229-245, 1997.

WILSON, G. D. Psychology for performing artists (2nd ed.). London: Whurr, 2002.

WILSON, G.D.; ROLAND, D. Performance anxiety. In: PARNCUTT, R.; MCPHERSON, G. 


\section{E. (Eds.), The science and psychology of music performance: Creative strategies for} teaching and learning. New York: Oxford University Press, p. 47-61, 2002.

YERKES, R. M.; DODSON, J. D. The relation of strengths of stimulus to rapidity of habit formation. Journal of Comparative Neurological Psychology, v. 18, n. 5, p. 459-482, 1908.

Apêndice

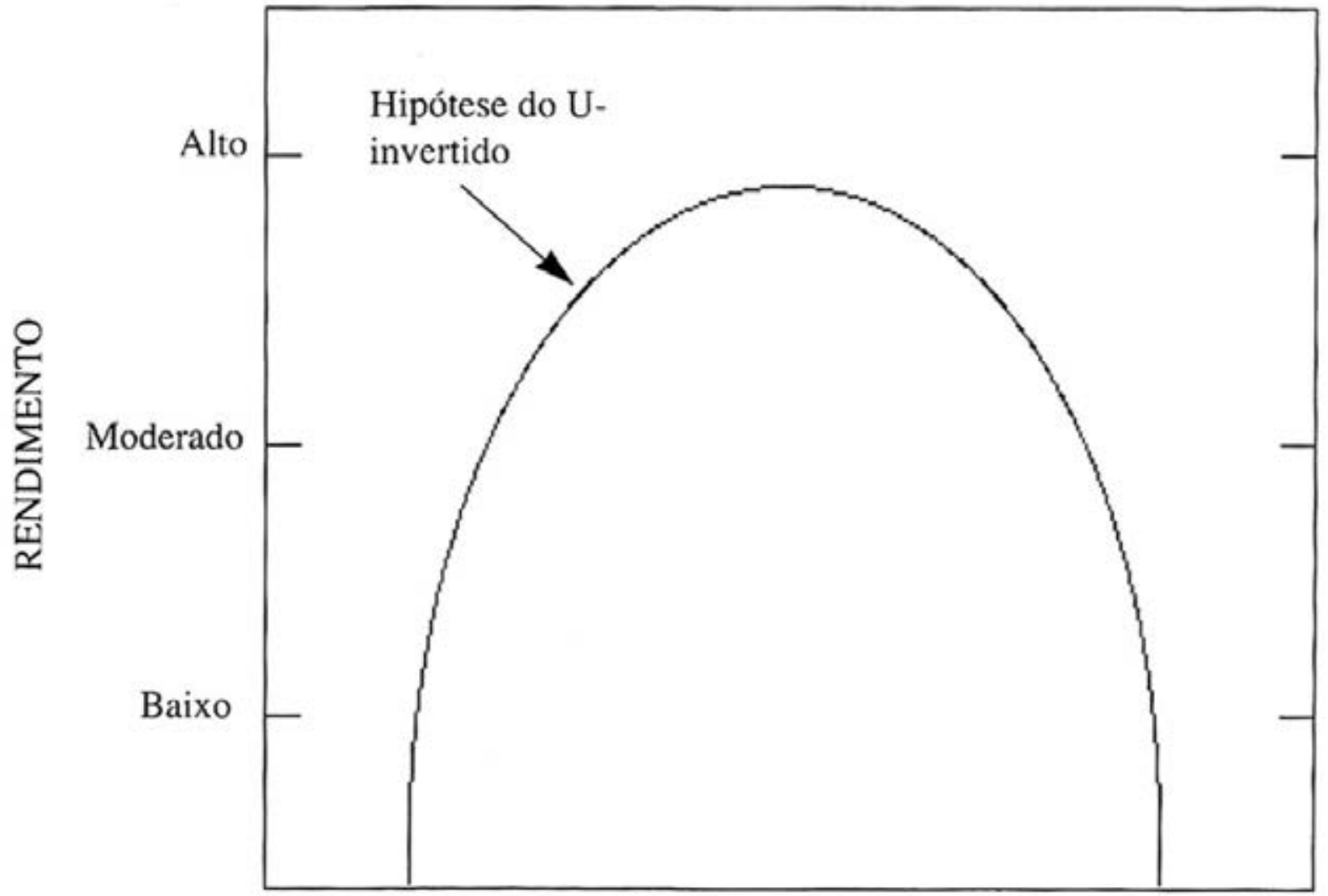

Fig. 1- Relação entre ativação e rendimento: teoria do U invertido.

Fonte: RODRIGUES, Maria. A ansiedade na performance musical: a perspectiva de pianistas profissionais Dissertação (Mestrado em Música) - Universidade Católica do Porto, Porto, 2009. p. 40. 